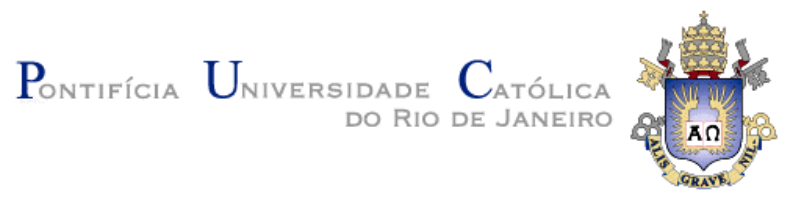

Cláudia Maria Barbosa

\title{
É Possível Distinguir Ética e Moral na Ethica Nicomachea de Aristóteles?
}

\author{
Dissertação de Mestrado
}

Dissertação apresentada como requisito parcial para obtenção do título de Mestre pelo Programa de PósGraduação em Filosofia da PUC-Rio.

Orientador: Prof. Danilo Marcondes de Souza Filho

Rio de Janeiro Abril de 2011 


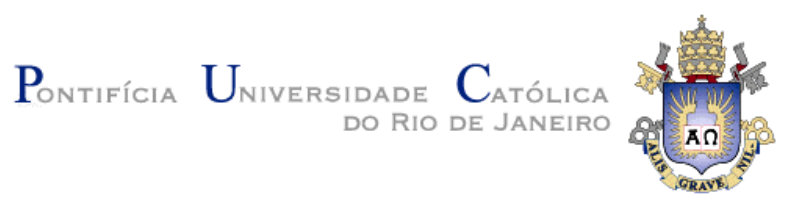

Cláudia Maria Barbosa

\title{
É Possível Distinguir Ética e Moral na Ethica Nicomachea de Aristóteles?
}

\begin{abstract}
Dissertação apresentada como requisito parcial para obtenção do título de Mestre pelo Programa de Pós-Graduação em Filosofia da PUC-Rio. Aprovada pela Comissão Examinadora abaixo assinada.
\end{abstract}

Prof. Danilo Marcondes de Souza Filho Orientador Departamento de Filosofia da PUC-Rio

Prof. Edgard José Jorge Filho Departamento de Filosofia da PUC-Rio

Profa. Inara Zanuzzi Universidade Federal do Paraná - UFPR

Profa. Denise Berruezo Portinari Coordenador Setorial do Centro de Teologia e Ciências Humanas - PUC-Rio 
Todos os direitos reservados. É proibida a reprodução total ou parcial do trabalho sem autorização da universidade, da autora e do orientador.

\section{Cláudia Maria Barbosa}

Graduou-se em Engenharia na Universidade Federal do Rio de Janeiro (UFRJ) em 1987. Especializou-se em Administração (PUC-Rio) em 1990 (Pós-Graduação Lato Sensu), e em Arte e Filosofia (PUC-Rio) em 2004 (PósGraduação Lato Sensu).

Ficha Catalográfica

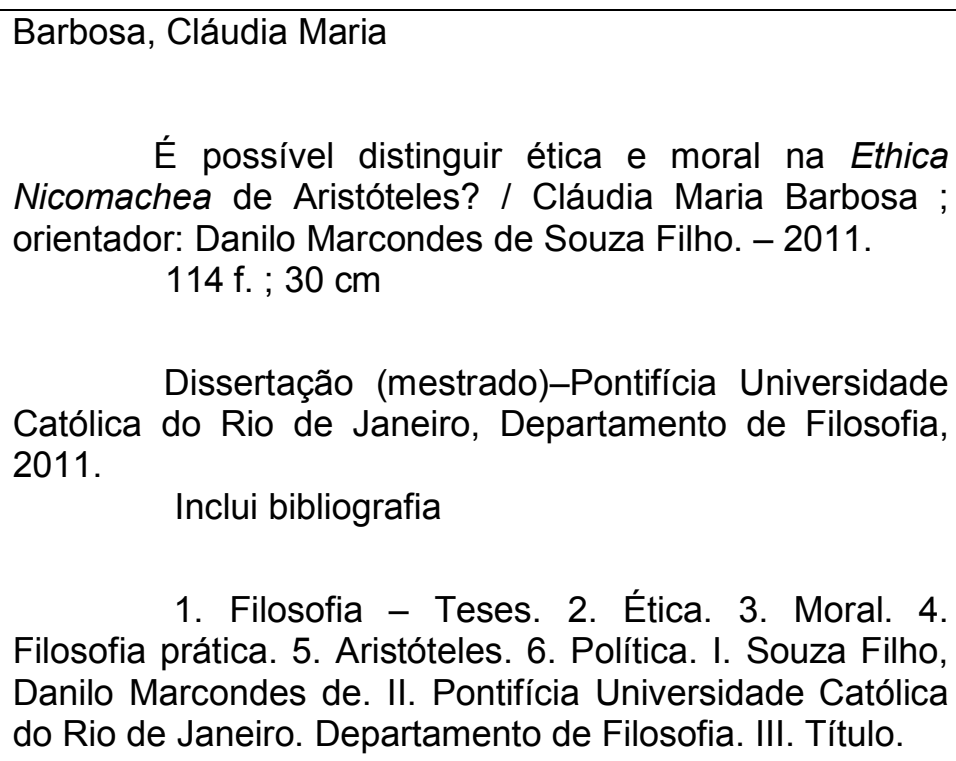




\title{
Agradecimentos
}

\author{
À minha orientadora e mestre, professora Barbara Botter, pelos preciosos \\ ensinamentos, estímulo e paciência; pela simplicidade, caráter e respeito no trato \\ com as pessoas e, sobretudo, pelo seu compromisso ético com a missão de \\ ensinar, de transmitir conhecimento. \\ Aos professores Danilo Marcondes, Edgard José e Inara Zanuzzi, que \\ participaram da Comissão Examinadora, pela generosidade da leitura atenta e \\ contribuições críticas.
}

Aos professores Carolina Araújo e Fernando Santoro pelas ótimas aulas no IFCS/UFRJ, e críticas ao trabalho que muito me ajudaram a enriquecê-lo.

Ao professor Carlo Natali pela leitura e observações que muito ajudaram a direcionar o desenvolvimento do trabalho.

Ao professor Antônio Abrantes (infelizmente não mais presente) pelas recomendações entusiasmadas para que eu ingressasse no mestrado em filosofia.

Ao professor Marcelo Cattan por uma conversa simples e sincera que, embora possivelmente ele não saiba, foi definitiva para minha dedicação a Aristóteles. 
Aos professores Edgar Lyra, Cristina Ribas, Irley Franco e Edson Resende que me ajudaram a dar os primeiros passos para este trabalho, através de indicações de leitura e orientação à monografia de especialização.

A todos os colegas, professores e funcionários do departamento de filosofia da PUC-Rio, pelo aprendizado e colaboração.

A todos os amigos que de uma forma ou outra me incentivaram e me apoiaram; em especial à Marcia Fixel pela leitura e releitura de várias partes do trabalho e conversas extremamente contributivas.

À presença próxima de uma mãe determinada e cheia de vida, depois de tanto tempo.

Às ausências sentidas neste último ano do trabalho: meu pai, Eduardo; e meu amigo, Flavio - minha eterna gratidão. 


\section{Resumo}

Barbosa, Claudia; Souza Filho, Danilo Marcondes de. É Possível Distinguir Ética e Moral na Ethica Nicomachea de Aristóteles? Rio de Janeiro, 2011. 114p. Dissertação de Mestrado - Departamento de Filosofia, Pontifícia Universidade Católica do Rio de Janeiro.

Este trabalho visa investigar se, em Aristóteles, e, sobretudo na Ethica Nicomachea $(E N)$, é possível encontrar elementos para a fundamentação dos conceitos atribuídos posteriormente à ética e à moral. Embora a virtude ética seja descrita de uma única forma em grego - êthikê aretê -, buscaremos trazer indicações de que já havia na EN diferentes manifestações de sua aplicação prática. Uma primeira manifestação seria a ação em consonância às leis gerais e aos costumes, que poderíamos relacionar à atual moral. Já a êthikê, em uma segunda manifestação, seria identificada a casos particulares, em que a lei não se aplica facilmente, mas o homem virtuoso é capaz de agir conforme a justa medida (mesotes). Esta idéia se apóia na cidade almejada por Aristóteles, em que caberá à Política orquestrar esta complexa êthikê.

\section{Palavras-chave}

Ética; moral; filosofia prática; Aristóteles; política. 


\section{Abstract}

Barbosa, Claudia; Souza Filho, Danilo Marcondes de (Advisor). Is it possible to make a distinction between wthics and moral in Aristotle's Ethica Nicomachea? Rio de Janeiro, 2011. 114p. Msc. Dissertation Departamento de Filosofia, Pontifícia Universidade Católica do Rio de Janeiro.

This paper aims at investigating if it is possible to find in Aristotle's work, especially in the Ethica Nicomachea $(E N)$, elements to substantiate the concepts that were later attributed to ethics and to moral. Although ethical virtue is uniquely described in Greek - êthikê aretê- we will seek to find evidence that different demonstrations of its practical application could already be found in the $E N$. The first demonstration would be acting in consonance with the general laws and customs, which could be related to today's moral. In a second demonstration, êthikê would be found in particular cases where the law could not be easily applied, but in which the virtuous person is capable of acting accordingly to the mean state (mesotes). This idea is supported by the city envisioned by Aristotle, where Politics would be responsible for orchestrating this complex êthikê.

\section{Keywords}

Ethics; moral; practical philosophy; Aristotle, politics. 


\section{Sumário}

1 Introdução

2 Parte I: Fundamentação 13

2.1. Como a tradição filosófica grega trata a ética? 16

2.2. Aroximação Ética e Natureza (physis) 21

2.3. Aproximação Ética e Política 32

2.4. Considerações Finais da Primeira Parte 44

3 Parte II: A Ética em Aristóteles e desdobramentos posteriores 48

3.1. Conceitos selecionados da Ética a Nicômaco (EN) 50

3.2. Justiça e equidade $\quad 67$

3.3. Inter-relação entre os conceitos selecionados da $E N \quad 75$

3.4. A delimitação do âmbito ético/moral face ao contexto 78

3.5. Considerações Finais da Segunda Parte 87

4 Parte III: Proposição 90

4.1. Definições propostas - "Ética 1" e "Ética 2" 91

4.2. Argumentação pela definição de virtude ética de Aristóteles (EN II 1106b 36 - 1107 a 2) 91

4.3. Teste da proposição, a partir do argumento, frente aos homens virtuosos e malvados indicados por Aristóteles na EN 97

4.4. Considerações Finais da Terceira Parte 103

5 Conclusão 106

6 Bibliografia 109

6.1. Básica 109

$\begin{array}{ll}\text { 6.2. Complementar } & 110\end{array}$ 